\title{
Quality of blood culture testing - a survey in intensive care units and microbiological laboratories across four European countries
}

\author{
Roland PH Schmitz ${ }^{1,2+}$, Peter M Keller, ${ }^{3,4+}$, Michael Baier ${ }^{3}$, Stefan Hagel ${ }^{5,6}$, Mathias W Pletz ${ }^{5,6}$
} and Frank M Brunkhorst ${ }^{1,2,6,7^{*}}$

\begin{abstract}
Introduction: Blood culture (BC) testing before initiation of antimicrobial therapy is recommended as a standard of care in international sepsis guidelines and has been shown to reduce intensive care unit (ICU) stay, antibiotic use, and costs in hospitalized patients. Whereas microbiological laboratory practice has been highly standardized, shortfalls in the preanalytic procedures in the ICU (that is indication, time-to-incubation, blood volume and numbers of $\mathrm{BC}$ sets) have a significant effect on the diagnostic yield. The objective of this study was to gain insights into current practices regarding $B C$ testing in intensive care units.
\end{abstract}

Methods: Qualitative survey, data collection by 138 semi-structured telephone interviews in four European countries (Italy, UK, France and Germany) between September and November 2009 in 79 clinical microbiology laboratories (LABS) and 59 ICUs.

Results: Whereas BC testing is expected to remain the gold standard for sepsis diagnostics in all countries, there are substantial differences regarding preanalytic procedures. The decision to launch BC testing is carried out by physicians vs. ICU nurses in the UK in 92 vs. $8 \%$, in France in 75 vs. $25 \%$, in Italy in 88 vs. $12 \%$ and in Germany in 92 vs. $8 \%$. Physicians vs. nurses collect BCs in the UK in 77 vs. 23\%, in France in 0 vs. 100\%, in Italy in 6 vs. $94 \%$ and in Germany in 54 vs. $46 \%$. The mean time from blood collection to incubation in the UK is $2 \mathrm{~h}$, in France $3 \mathrm{~h}$, in Italy $4 \mathrm{~h}$, but $20 \mathrm{~h}$ in German remote LABs ( $2 \mathrm{~h}$ in in-house LABs), due to the large number of remote nonresident microbiological laboratories in Germany. There were major differences between the perception of the quality of $B C$ testing between ICUs and LABs. Among German ICU respondents, 62\% reported that they have no problems with BC testing, $15 \%$ reported time constraints, $15 \%$ cost pressure, and only $8 \%$ too long time to incubation. However, the corresponding LABs of these German ICUs reported too many false positive results due to preanalytical contaminations (49\%), insufficient numbers of incoming BC sets (47\%), long transportation time (41\%) or cost pressure (18\%).

Conclusions: There are considerable differences in the quality of BC testing across European countries. In Germany, time to incubation is a considerable problem due to the increasing number of remote LABs. This is a major issue of concern to physicians aiming to implement sepsis guidelines in the ICUs.

\footnotetext{
* Correspondence: frank.brunkhorst@med.uni-jena.de

${ }^{\dagger}$ Equal contributors

${ }^{1}$ Center of Clinical Studies, Jena University Hospital, Salvador-Allende-Platz 27,

07747 Jena, Germany

2Paul-Martini Sepsis Research Group, Jena University Hospital,

Salvador-Allende-Platz 27, 07747 Jena, Germany

Full list of author information is available at the end of the article
} 


\section{Introduction}

Blood culture (BC) testing before initiation of antimicrobial therapy is recommended as a standard of care in international sepsis guidelines [1] and has been shown to contribute to a decrease in ICU stay [2-4]. Furthermore, $\mathrm{BC}$ testing is one of the cornerstones for antibiotic stewardship programs, which has been shown to reduce antibiotic overuse and costs in hospitalized patients [5,6].

Beside limitations of $\mathrm{BC}$ testing, for example antibiotic/antimycotic treatment prior to sampling, low proportion of causative agents in the blood samples, and frequent fastidious or noncultivable organisms [7-9], a high degree of standardization in microbiological laboratory (LAB) practice warrants for an overall positivity of approximately 30 to $40 \%$ in case of severe sepsis or septic shock [10]. In a recent large multicenter trial from Germany [11] 33\% of patients with severe sepsis or septic shock had proven bacteremia. This is in contrast to a rate of only $9.6 \%$ of positive blood cultures observed in clinical practice in German ICUs aside from protocolized care [12] and underlines shortfalls in the preanalytic procedures in the ICU. Such shortfalls cover inadequate skin antisepsis and sampling techniques, as access via intravenous catheters, low blood volumes and low numbers of $\mathrm{BC}$ sets drawn for inoculation, prolonged time to incubation, suboptimal preincubation prior to automated cultivation at $37^{\circ} \mathrm{C}$, which have a significant effect on the diagnostic yield [13-15].

The numbers of $\mathrm{BC}$ sets processed per hospitalized patients are off particular importance. According to the case mix of the hospital, inoculation of 100 to 200 BC sets per 1,000 patient days is recommended [16,17]. These numbers are, however, far from routine use, at least in Germany, where 55 BCs per 1,000 patient days were surveyed in 201 ICUs in 2009 in contrast to France, where 165 BCs per 1,000 patient days were quoted [18]. The 2010 annual report of the European Antimicrobial Resistance Surveillance Network (EARSNet) specified only $12.1 \mathrm{BCs}$ per 1,000 patient days in 37 hospitals in Germany, compared to 46.5 in 27 hospitals in France, 46.1 in 26 hospitals in the UK, and 70.7 BCs per 1,000 patient days in 22 hospitals in Italy [19]. In a recent study published by the National Reference Centre for Hospital Infections (NRZ), data of the German hospital nosocomial infection surveillance system (KISS) from 2006 were used to investigate the association between the frequency of blood cultures and central venous catheter-associated bloodstream infection (CVC-BSI) rates in 223 intensive care units (ICU) [20]. The median number of $\mathrm{BC}$ sets taken was 60 with a huge variation from 3.2 to 680 per 1,000 patient days. The authors concluded that if an external benchmarking of CVCBSI rates is intended, an adjustment according to the $\mathrm{BC}$ frequency is necessary.
Reasons for the disregard of current guidelines have been identified, among others, in infrastructural aspects. The number of infections confirmed by LABs closely depends on the availability of closely located LABs [12], which sets a focus for future improvements of uniform customs and recommendations and of technical procedures on the preanalytic side of $\mathrm{BC}$ routine. Furthermore, there may be differences in the quality of $\mathrm{BC}$ testing between countries since the establishment of clinical microbiology and infectious disease departments vary substantially among European countries. Especially in Germany, patient-centered clinical microbiology is only a branch of laboratory medicine [21].

The aim of this qualitative survey was to assess the current practice in $\mathrm{BC}$ testing in ICUs and LABs across four European countries. Issues were technical aspects of the preanalytic course and an assessment of the current practice and their quality on the basis of individual perceptions among the staff and directors of ICUs versus LABs.

\section{Materials and methods}

Some 138 interviews were conducted between September and November 2009 in 79 microbiological laboratories (LABs) and 59 intensive care units (ICUs) in France, Germany, Italy, and UK (Table 1). Pediatric and neonatal ICUs were excluded. Interviewees were ICU directors, ICU residents, ICU nurses, LAB directors, and LAB managers. The survey was carried out by an international agency (Advention BP, London, UK) on behalf of BD Diagnostics (Heidelberg, Germany). To uncover prevalent trends in thought and opinion, the interview panel was selected to fulfill a given quota, for example per country 10 to 20 ICUs and microbiological laboratories, respectively. Furthermore, the panel had to be balanced between BD Diagnostics (49.5\%) and bioMérieux (Craponne, France) (50.5\%) customers. Data were collected using semistructured techniques for example individual in-depth personal telephone interviews. The interview guide included, among others, a list of general topics and open questions such as sepsis awareness and indication for BC testing, preanalytic procedures, sample transport and preincubation, and $\mathrm{BC}$ processing and communication of results (see Table S1 in Additional file 1). The response rate was 100 percent, since personal interviews have the potential to overcome the poor response rates of a questionnaire survey [22]. According to the requirements of the ethics committee of Jena University Hospital (Jena, Germany), the survey needed no ethical approval.

\section{Results}

\section{Sepsis awareness}

Throughout all countries surveyed, sepsis and its timely diagnosis are considered as top priorities for both ICUs 
Table 1 Interviewees participating in the survey

\begin{tabular}{|c|c|c|c|c|c|}
\hline Interviewees (n) & France & Germany & Italy & UK & Total \\
\hline Total (n) & 39 & 32 & 30 & 37 & 138 \\
\hline ICUs (n) & 16 & 13 & 17 & 13 & 59 \\
\hline LABs (n) & 23 & 19 & 13 & 24 & 79 \\
\hline \multicolumn{6}{|c|}{ Type of structure (\%) } \\
\hline Private & 10 & 37 & 0 & 0 & 12 \\
\hline Public & 90 & 63 & 100 & 100 & 88 \\
\hline \multicolumn{6}{|l|}{ ICUs } \\
\hline Private & 0 & 23 & 0 & 0 & 5 \\
\hline Public & 100 & 77 & 100 & 100 & 95 \\
\hline \multicolumn{6}{|l|}{ LABs } \\
\hline Private & 17 & 47 & 0 & 0 & 16 \\
\hline Public & 83 & 53 & 100 & 100 & 84 \\
\hline \multicolumn{6}{|c|}{ Interviewee position (n) } \\
\hline \multicolumn{6}{|l|}{ ICUs } \\
\hline Head of ICU & 3 & 6 & 0 & 0 & 9 \\
\hline Physician & 7 & 7 & 12 & 12 & 38 \\
\hline Nurse & 6 & 0 & 5 & 1 & 12 \\
\hline \multicolumn{6}{|l|}{ LABs } \\
\hline LAB director & 8 & 17 & 5 & 5 & 35 \\
\hline LAB manager & 5 & 0 & 3 & 15 & 23 \\
\hline Microbiologist & 10 & 2 & 5 & 4 & 21 \\
\hline
\end{tabular}

LAB, microbiological laboratory.

and LABs. Sepsis awareness is perceived as increasingly important for $46 \%$ of interviewees in the UK, $43 \%$ in Italy, and 30\% in Germany, due to its high incidence and mortality, and the importance of timely diagnosis for recovery. Medical staff in all countries noted increasing efforts how to detect and treat sepsis and how to implement educational programs for infection control in their hospitals. In the UK, critical care outreach teams have been established in certain hospitals in order to increase the medical staff's awareness throughout the hospital [23].

\section{Indication for BC testing}

All interviewees claimed that in their institutions BCs are collected and broad-spectrum antibiotics are administered immediately, if sepsis is suspected clinically. In general, the four systemic inflammatory response syndrome (SIRS) criteria of body temperature (fever $\left(\geq 38^{\circ} \mathrm{C}\right)$ or hypothermia $\left(\leq 36^{\circ} \mathrm{C}\right)$ ), heart rate (tachycardia $\geq 90$ heartbeats per minute), respiratory rate (tachypnea $\geq 20$ breaths/minute or hyperventilation $\mathrm{pCO}_{2}<36 \mathrm{mmHg}$ ), and white blood cell count (leucocytosis $(>12,000$ cells $/ \mu \mathrm{l})$, leucocytopenia $(<4,000$ cells $/ \mu \mathrm{l})$, presence of immature neutrophiles) are monitored. The presence of one suspicious sign (especially the presence of fever) is usually sufficient to launch a $\mathrm{BC}$. If more than one sign is present, a systematic workup is initiated. Further standard cultures (for example, urine, tracheal specimen, wound, cerebral fluids, and other swabs) are regularly performed.

\section{Preanalytic procedures \\ Numbers of BCs cultured}

Most ICUs claimed to collect between two and three BC sets per patient with varying numbers by country (Figure 1). In contrast, wards collect only between 1.3 (Germany) and 1.8 (France) BC sets per patient. Less than $15 \%$ of ICUs claimed to collect less than two BC sets per patient. ICUs account for a significant proportion of $\mathrm{BC}$ sets processed in LABs, ranging from $15 \%$ in the UK to $33 \%$ in Germany.

\section{Launch of $B C s$}

Considerable country-specific differences were identified regarding $\mathrm{BC}$ collection and processing, including transportation to the LAB, timely feedback and communication procedures of results back to the ICU. While the decision to order a BC is typically taken by physicians in all countries, blood sampling is mainly carried out by physicians in the UK, by nurses in France and Italy, and by both in Germany (Table 2).

\section{Sampling technique}

Techniques for blood sampling vary across countries (Table 2). A fresh peripheral venipuncture is more preferred in Germany and Italy, while blood collection via an intravenous catheter is more preferred in France and the UK. For collection, traditional systems (that is syringe

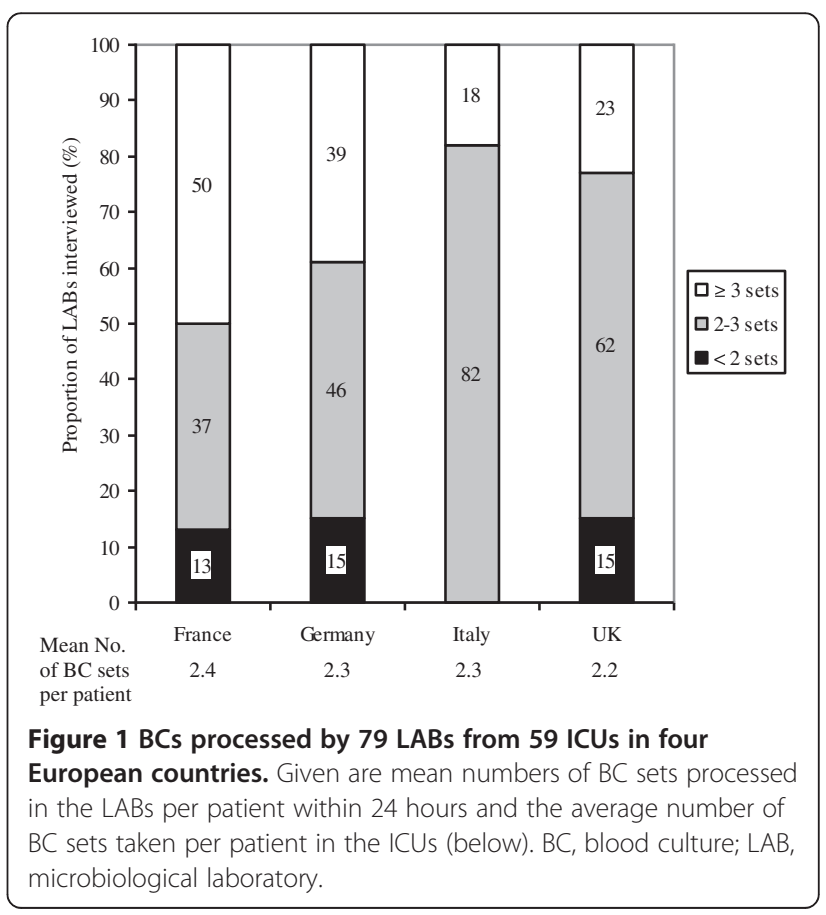


Table 2 Collection, transport and processing of $\mathrm{BCs}$ in four European countries

\begin{tabular}{|c|c|c|c|c|}
\hline & France & Germany & Italy & UK \\
\hline \multicolumn{5}{|l|}{ Sample transport } \\
\hline \multicolumn{5}{|l|}{ Time to incubation (h) } \\
\hline On-site LABs & 3 & 2 & 4 & 2 \\
\hline Remote LABs & - & 20 & - & - \\
\hline \multicolumn{5}{|l|}{$\begin{array}{l}\text { Cultures incubated with a } \\
\text { delay of }>8 \mathrm{~h}(\%)\end{array}$} \\
\hline On-site LABs & 9 & 10 & 9 & 6 \\
\hline Remote LABs & - & $>60$ & - & - \\
\hline \multicolumn{5}{|l|}{ Modes of transportation (\%) } \\
\hline Van & 36 & 71 & 23 & 15 \\
\hline Porter & 32 & 0 & 77 & 50 \\
\hline Pneumatic tube & 32 & 29 & 0 & 35 \\
\hline \multicolumn{5}{|l|}{ LAB opening hours (\%) } \\
\hline 8 h 5 days per week & 41 & 40 & 31 & 19 \\
\hline 8 h 7 days per week & 41 & 40 & 46 & 62 \\
\hline $24 \mathrm{~h} 7$ days per week & 18 & 20 & 23 & 19 \\
\hline \multicolumn{5}{|l|}{ BC management outside } \\
\hline \multicolumn{5}{|l|}{ LAB opening hours (\%) } \\
\hline Storage at room temperature & 73 & 86 & 67 & 27 \\
\hline \multicolumn{5}{|l|}{ (up to $12 \mathrm{~h}$ delay) } \\
\hline Access to $B C$ system in the $L A B$ & 27 & 0 & 33 & 73 \\
\hline \multicolumn{5}{|l|}{ (1 $\mathrm{h}$ delay) } \\
\hline $\begin{array}{l}\text { Access to BC system in the } \\
\text { ICU (no delay) }\end{array}$ & 0 & 14 & 0 & 0 \\
\hline \multicolumn{5}{|l|}{$\begin{array}{l}\text { Interest in relocation of BC } \\
\text { systems into ICU (\%) }\end{array}$} \\
\hline LABs & 22 & 47 & 33 & 21 \\
\hline ICUs & 17 & 88 & 86 & 0 \\
\hline \multicolumn{5}{|l|}{ Decision to launch BC (\%) } \\
\hline Physician & 75 & 92 & 88 & 92 \\
\hline Nurse & 25 & 8 & 12 & 8 \\
\hline \multicolumn{5}{|l|}{ Responsible for BC collection (\%) } \\
\hline Physician & 0 & 54 & 6 & 77 \\
\hline Nurse & 100 & 46 & 94 & 23 \\
\hline \multicolumn{5}{|l|}{ Mode of BC collection (\%) } \\
\hline Intravenous catheter only & 33 & 8 & 0 & 23 \\
\hline Peripheral venipuncture only & 20 & 42 & 76 & 23 \\
\hline Both & 47 & 50 & 24 & 54 \\
\hline
\end{tabular}

$\mathrm{BC}$, blood culture; $\mathrm{LAB}$, microbiological laboratory.

and needle) or closed systems (that is winged collection sets, vacuum systems) are used in all countries. Closed systems are primarily used in France (71\%), whereas Germany has the highest rate in the usage of syringes and needles (42\%).

\section{Blood volumes collected}

Blood volumes collected per bottle vary between an average of $8.3 \mathrm{ml}$ in France to $11.5 \mathrm{ml}$ in Italy, while the majority of ICUs collect 8 to $12 \mathrm{ml}$ of blood per bottle as requested by the LABs. Some $86 \%$ of the ICUs are aware that pathogen detectability is directly proportional to the amount of blood volume per bottle taken (Figure 2).

\section{Sample transport and preincubation}

Time to incubation depends on transportation time, $\mathrm{LAB}$ opening hours, and $\mathrm{BC}$ management outside these timelines. Time-to-incubation ranges from $2 \mathrm{~h}$ in the UK and up to $20 \mathrm{~h}$ in German remote nonresident LABs (Table 2). For transportation, mainly vehicles/vans are used in Germany, where 23\% of LABs are private, nonresident LABs. In Italy and in the UK transport service personnel is predominantly responsible for $\mathrm{BC}$ transportation within the hospital. In-house pneumatic tube systems are used in an about one-third of hospitals in France, Germany and the UK, but are not available or not used in Italy for $\mathrm{BC}$ transportation (Table 2).

The majority of LABs are closed overnight in all countries. Only about $40 \%$ offer services on weekends, with the exception of UK, where $62 \%$ are opened during weekends. Many LABs have on-call services for infectious emergencies. However, this service is rarely available for $\mathrm{BC}$ testing and management. Accordingly, the majority of $\mathrm{BCs}$ are stored at room temperature outside LAB opening hours, except in the UK where cultures are often preincubated in the LAB, which is served

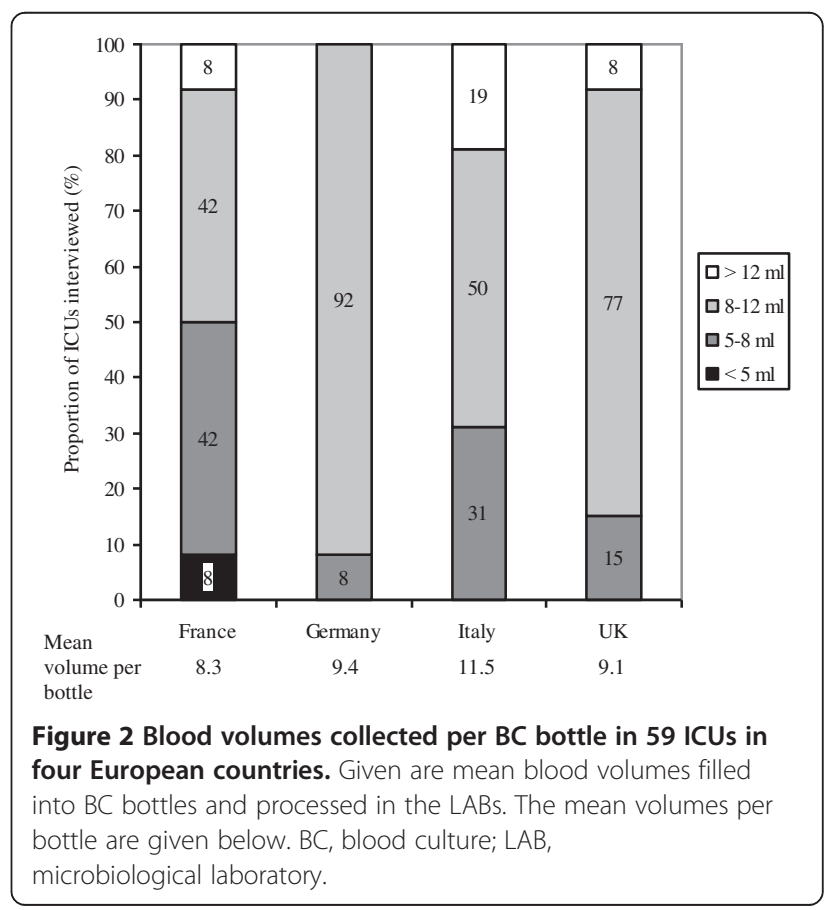


by the transport service personnel. Due to the high number of private nonresident LABs in Germany, $14 \%$ of German ICUs have established a local BC incubator device in order to shorten time to incubation. Remarkably, $88 \%$ of German and $86 \%$ of Italian ICUs are interested in the relocation of the $\mathrm{BC}$ incubation device at their ICUs. This is also supported by $47 \%$ of German and 33\% of Italian LABs. The interest is considerably lower in the UK (ICUs: 0\%, LABs: 21\%) and in France (17\%/22\%) (Table 3).

\section{BC processing, report of results and communication strategies}

On average, LABs process $50 \mathrm{BC}$ sets per day, ranging from 35 in the UK to 58 in Germany with a positivity rate of 12 to $13 \%$. However, identification and antibiotic susceptibility testing (ID/AST) is not performed on all positive cultures (9\% in France, 13\% in Germany and Italy and $12 \%$ in the UK) (Figure 3 ).

Positive culture results are usually communicated over the phone across all countries, while ID/AST results are communicated to the physicians only in the UK, France, and Italy. Negative results are poorly communicated immediately, but are sent out as a written report at the

\section{Table 3 Major challenges regarding BC testing in sepsis routine identified in 79 ICUs and 59 LABs across four European countries}

\begin{tabular}{lcccc}
\hline Challenges (\%) & France & Germany & Italy & UK \\
\hline ICUs & 50 & $\mathbf{6 2}$ & 18 & 38 \\
No challenges & 19 & 15 & $\mathbf{4 1}$ & 8 \\
Time constraints & 0 & 15 & $\mathbf{4 1}$ & 15 \\
Cost pressure & 0 & 0 & 18 & $\mathbf{3 1}$ \\
Insufficient training of personnel & 0 & 8 & $\mathbf{1 2}$ & 0 \\
Excessive time to transport & $\mathbf{1 3}$ & 0 & 6 & 0 \\
Poor communication with LAB & $\mathbf{2 5}$ & 0 & 6 & 8 \\
Other & & & & \\
LABs & 19 & 31 & 18 & $\mathbf{4 6}$ \\
No challenges & 4 & $\mathbf{3 7}$ & 23 & 0 \\
Excessive time to transport & $\mathbf{4 3}$ & 42 & 0 & 21 \\
Insufficient incoming sample & & & & \\
volumes/number of BC sets & 9 & 16 & $\mathbf{5 4}$ & 29 \\
Cost pressure & 13 & 0 & $\mathbf{2 3}$ & 4 \\
Mislabeling of BC bottles & 9 & $\mathbf{2 1}$ & 8 & 17 \\
Many false negatives & & & & \\
Many false positives due to & $\mathbf{9}$ & 0 & 8 & 0 \\
$\quad$ Inappropriate taking of blood samples & $\mathbf{6 1}$ & 53 & 0 & 38 \\
Delayed transport to the LAB & $\mathbf{9}$ & $\mathbf{1 1}$ & 0 & 4 \\
\hline Low reactivity of clinicians & 0 & &
\end{tabular}

BC, blood culture; LAB, microbiological laboratory. end of the analysis. The quality of interaction between the $\mathrm{LAB}$ and the ICU is perceived as very good in all countries except in Germany, where microbiologists complain about the poor reactivity of clinicians, when positive $\mathrm{BCs}$ require discussion and some German ICU physicians complain about the poor quality of communication with LABs, leading to delayed or incomplete transmission of results (Table 3).

In general, perceptions vary substantially between ICU physicians and LABs (Table 3). Some $42 \%$ of ICU physicians do not see any challenges in $\mathrm{BC}$ testing, compared to $29 \%$ of LAB physicians, who address several severe limitations in $\mathrm{BC}$ testing, especially in Germany.

LABs acknowledge the insufficient incoming number of $\mathrm{BC}$ sets and blood volumes (27\%), the high rate of false positives due to non-proper skin antiseptics and collection via intravenous catheters (38\%), and the cost pressure, limiting the type and number of BC sets (27\%). Cost pressure is a major challenge in Italy, where $41 \%$ of ICUs and $54 \%$ of LABs agree upon this limitation.

Excessive time to transport from the ICU to the LAB is a major challenge especially in Germany and Italy (37\% and 23\%). Germany and France have the highest rates in insufficient numbers of $\mathrm{BC}$ sets and low blood volumes taken $(42 \%$ and $43 \%)$ and the highest rates of false positive BCs due to inappropriate taking of blood samples (53\% and 61\%).

Notably, in the UK, LABs have a strong role in the decision to initiate antibiotic treatment, while in France and Germany ICU physicians are more responsible in their choice of antibiotics.

\section{Discussion}

Blood culture testing is definitively the gold standard and primary test to evaluate patients with sepsis [24]. However, despite European efforts to standardize BC testing similar to the US Clinical and Laboratory Standards Institute (CLSI) guidelines [17], there are different perceptions regarding the performance of $\mathrm{BC}$ testing between the interviewees from four European countries in our survey.

The S2k guidelines of the German Sepsis Society (GSS) [25] (see Table S2 in Additional file 2), the Italian Progetto LaSER [26], and the Britain Saving Lives (NHS) guidelines [27] recommend $\geq 2 \mathrm{BC}$ sets in case of sepsis suspicion, which is supported by the recent international guidelines of the Surviving Sepsis Campaign (SSC) [1], whereas the French National Society of Anaesthesia and Intensive Care (SFAR) give no recommendations.

Major challenges in BC testing are low rates of true positivity due to antibiotic pretreatment prior to blood withdrawal, suboptimal sample volume, an inadequate number of $\mathrm{BC}$ bottles cultured and delays in time to incubation. 


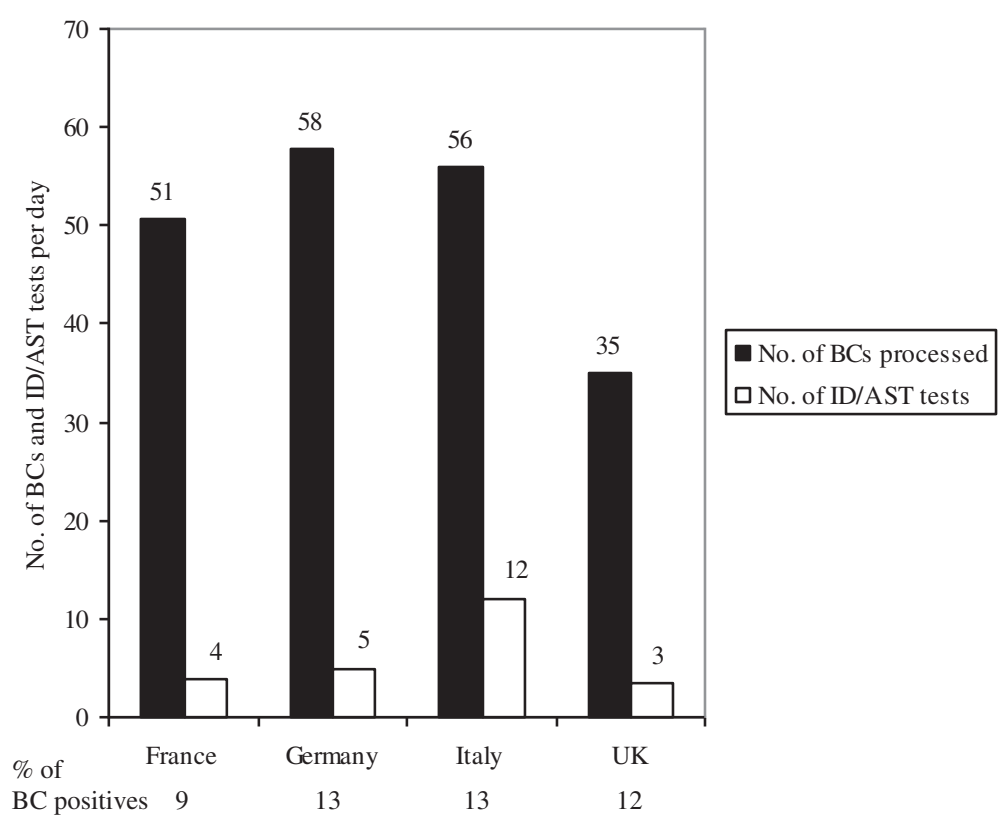

Figure 3 Number of BC sets processed and ID/AST tests performed per day (mean) in microbiological LABs in four European countries. The mean percentage of positive BC sets processed per day and LABs are given below. BC, blood culture; ID/AST, identification and antibiotic susceptibility testing; $L A B$, microbiological laboratory.

In a French monocentric study, Vitrat-Hincky et al. found that only $45 \%$ of patients had adequate numbers of $\mathrm{BC}$ sets and only $13 \%$ had optimal sample volumes (that is $\geq 10 \mathrm{ml}$ per bottle) [28]. The authors of a review on true-positive rate, contamination rate, and collected blood volume of $\mathrm{BC}$ bottles in five Belgian hospital laboratories found that more than one-third of the $\mathrm{BC}$ bottles handled were incorrectly filled, irrespective of the manufacturer of the blood culture vials [29].

In our survey, blood volumes collected per BC bottle varied considerably between countries with on average less than $10 \mathrm{ml}$ per bottle $(8.3 \mathrm{ml}$ in France, Italy with $11.5 \mathrm{ml}$ as an exception), though ICU staff is aware of the fact that $\mathrm{BC}$ positivity is proportional to the blood volume taken.

Differences in qualities of recommended blood sampling for BCs (number of sets and volume per bottle) may be partly explained by different responsibilities among the ICU staff. BC sampling is mainly carried out by physicians in the UK, by nurses in France and Italy, and by both in Germany.

In our survey, time to incubation of $\mathrm{BCs}$ ranged from $2 \mathrm{~h}$ in the UK and up to $20 \mathrm{~h}$ in German remote LABs. Limitations in transport times for BCs had been reported by Kerremans et al. in the Netherlands [30]. The median transport time in this study was $3.5 \mathrm{~h}$, with $47 \%$ of cultures exceeding the recommended $4 \mathrm{~h}$. Off-site location and type of clinical specialty were the most important predictors of long transport times. Cultures collected during weekend days or on wards at the largest distances from the laboratory were also associated with long transport times.

Considerable differences between countries were observed with regard to blood transport and storage prior to automated incubation in our survey. Delays in transport times were mainly due to different transport modes (that is, via van, porter, or pneumatic tube) and infrastructure. With Germany as an obvious exception, LABs are usually closely related to hospitals resulting in a transport time $\leq 4 \mathrm{~h}$. Together with a general trend to store blood during closing times at room temperature, which accounts for a further delay of $\leq 12 \mathrm{~h}$, up to $20 \mathrm{~h}$ time to incubation occurs in Germany. In consequence, up to $14 \%$ of German ICUs already have direct access to an on-site BC incubation device. The impact of immediate incubation of $\mathrm{BCs}$ delivered to the laboratory outside its hours of operation on turnaround times, antibiotic prescription practices, and patient outcomes was assessed by Kerremans et al. in a study from the Netherlands [31]. The authors found no difference in length of stay or hospital mortality, but immediate incubation of BCs outside laboratory hours reduced turnaround times and accelerated antibiotic switching.

Positive BC results are of paramount importance for patient management. Similarly to surgery, where the close cooperation with the pathologists of hospitals guarantees the intraoperative rapid section with immediate diagnosis within a few hours, $\mathrm{BC}$ results have to be considered as 
emergencies. It is therefore mandatory to notify a clinical professional (physician, nurse practitioner) responsible for the coordination of $\mathrm{BC}$ testing between LABs and ICUs.

Furthermore, since many patients are seen at an emergency department at first instance and initial $\mathrm{BCs}$ are taken there, it is the responsibility of the LABs to determine the location of the patient once the cultures are positive. Our survey shows that most LABs transmit preliminary results (that is, on Gram-staining behavior of the microorganisms grown in culture) via telephone, allowing clinical professionals to fine-tune the initial empiric antibiotic treatment. Final results, including ID/ AST information, are mostly sent via facsimile or as a written letter report. This is due to the complex nature of the information (resistance-testing results for $>10$ antibiotics) and to time and cost reasons. Direct oral or face-to-face communication is established in all interviewees' countries except Germany. However, improving communication of $\mathrm{BC}$ results (including negative results) have been shown to reduce antibiotic usage in neonatal intensive care units [32]. Telephone transmission of critical laboratory results may be inaccurate. However, a study by Howe et al. showed only minor transmission errors [33].

Our study has several limitations. First, aberrations from guidelines may notably in part be due to the general phenomenon that treatment recommendations in ICUs only poorly comply with practice recommendations: ICU directors perceive adherence to be higher than it actually is [34]. We did not perform an audit on order to assess actual practice. However, the results of this survey show that even perception of current BC practices in European ICUs is suboptimal. Second, the survey was qualitative in nature, so only semi-structured techniques with open questions were applied and respondents were not randomly selected and our findings are not representative. For instance, the proportion of $\mathrm{BC}$ sets processed in LABs is influenced by the case mix of ICUs. In addition, we have no quantitative data on preanalytic procedures, that is, contamination data, blood volume, and routine practice subsequent to inoculation of $\mathrm{BC}$ bottles. Furthermore, due to the exploratory outcome of our research, a statistical analysis was not performed and our data cannot be used to make generalizations. However, by providing insights into BC testing practices in European ICUs, our study generates ideas and hypotheses for later quantitative research. Finally, we did not assess knowledge and attitudes concerning interpretation of $\mathrm{BC}$ results and, more importantly, therapeutic consequences. However, guideline-based collection, processing and reporting of $\mathrm{BCs}$ are the cornerstones for successful patient management [35].

\section{Conclusions}

Evidence-based blood culture testing is of utmost importance for ICU patients with suspected sepsis. Knowledge of the etiologic agent (bacteria or fungi) and their susceptibility against antimicrobials enables the clinician to initiate an appropriate antimicrobial therapy and to guide diagnostic procedures. Whereas microbiological laboratory practice has been highly standardized, shortfalls in the preanalytic procedures in the ICU (indication, timing, volume, numbers, collection of blood cultures) have a significant effect on the diagnostic yield. Implementation strategies involving all ICU staff are needed to overcome the gap between recommended best practices and national guidelines. Finally, the BC frequency per 1,000 patient days should be established as a quality indicator in ICUs.

\section{Key messages}

- There are considerable differences in the quality of $\mathrm{BC}$ testing across European countries and also in the perception of the quality of $\mathrm{BC}$ testing between ICUs and LABs.

- Positive BC results are of paramount importance for patient management. Rapid communication of BC results has to be considered as an emergency. Implementation strategies involving all ICU staff are needed to improve $\mathrm{BC}$ testing.

- If an external benchmarking of CVC-BSI rates is intended, an adjustment according to the $\mathrm{BC}$ frequency is necessary.

\section{Additional files}

Additional file 1: Table S1. Issues addressed in the interview guide. Additional file 2: Table S2. Guideline-based blood culture testing (according to [10]).

\section{Abbreviations}

BC: Blood culture; CVC-BSI: Central venous catheter-associated bloodstream infection; ICU: Intensive care unit; ID/AST: Identification and antibiotic susceptibility testing; LAB: Microbiological laboratory.

\section{Competing interests}

The authors declare that they have no competing interests. The Paul-Martini Sepsis Research Group has been supported by unrestricted grants of BD Diagnostics, Heidelberg, Germany.

\section{Authors' contributions}

RPHS participated in the study concept and design, contributed to the analysis and interpretation of data, drafted the manuscript and critically revised it for important intellectual content, and provided statistical expertise. PMK contributed to the analysis and interpretation of data, drafted the manuscript and critically revised it for important intellectual content. MB contributed to the analysis and interpretation of data, critically revised the manuscript for important intellectual content, and provided administrative, technical, or material support. SH contributed to the analysis and interpretation of data, critically revised the manuscript for important intellectual content, and provided administrative, technical, or material 
support. MWP contributed to the analysis and interpretation of data, critically revised the manuscript for important intellectual content, and provided administrative, technical, or material support. FMB participated in the study concept and design, contributed to the analysis and interpretation of data, drafted the manuscript and critically revised it for important intellectual content, and provided statistical expertise and study supervision. All authors read and approved the final manuscript.

\section{Acknowledgements}

This study was supported by the Paul Martini Sepsis Research Group, which is funded by the Thuringian Ministry of Education, Science and Culture (ProExcellence; grant PE 108-2); the publically funded Thuringian Foundation for Technology, Innovation and Research (STIFT) and the German Sepsis Society (GSS); the German Ministry of Health (BMG; grant INFEKT 039) the Jena Center of Sepsis Control and Care (CSCC), which is funded by the German Ministry of Education and Research (BMBF; grant 01 EO 1002). Advention BP, London on behalf of BD Diagnostics, contributed to the acquisition of data.

\section{Author details}

${ }^{1}$ Center of Clinical Studies, Jena University Hospital, Salvador-Allende-Platz 27 07747 Jena, Germany. ${ }^{2}$ Paul-Martini Sepsis Research Group, Jena University Hospital, Salvador-Allende-Platz 27, 07747 Jena, Germany. ${ }^{3}$ Institute of Medical Microbiology, Jena University Hospital, Erlanger Allee 101, 07747 Jena, Germany. ${ }^{4}$ Department of Gastroenterology and Hepatology, Jena University Hospital, Erlanger Allee 101, 07747 Jena, Germany. ${ }^{5}$ Center of Infectious Diseases and Hospital Hygiene, Jena University Hospital, Erlanger Allee 101, 07747 Jena, Germany. ${ }^{6}$ Center of Sepsis Control and Care (CSCC), Jena University Hospital, Salvador-Allende-Platz 27, 07747 Jena, Germany. ${ }^{7}$ Department of Anesthesiology and Intensive Care Medicine, Jena University Hospital, Erlanger Allee 101, 07747 Jena, Germany.

Received: 22 May 2013 Accepted: 25 September 2013

Published: 21 October 2013

\section{References}

1. Dellinger RP, Levy MM, Rhodes A, Annane D, Gerlach H, Opal SM, Sevransky JE, Sprung CL, Douglas IS, Jaeschke R, Osborn TM, Nunnally ME, Townsend SR, Reinhart K, Kleinpell RM, Angus DC, Deutschman CS, Machado FR, Rubenfeld GD, Webb SA, Beale RJ, Vincent JL, Moreno R, Surviving Sepsis Campaign Guidelines Committee including the Pediatric Subgroup: Surviving sepsis campaign: international guidelines for management of severe sepsis and septic shock: 2012. Crit Care Med 2013, 41:580-637.

2. Ferrer R, Artigas A, Levy MM, Blanco J, González-Díaz G, Garnacho-Montero J, Ibáñez J, Palencia E, Quintana M, de la Torre-Prados MV, Edusepsis Study Group: Improvement in process of care and outcome after a multicenter severe sepsis educational program in Spain. JAMA 2008, 299:2294-2303.

3. Meehan TP, Fine MJ, Krumholz HM, Scinto JD, Galusha DH, Mockalis JT, Weber GF, Petrillo MK, Houck PM, Fine JM: Quality of care, process, and outcomes in elderly patients with pneumonia. JAMA 1997, 278:2080-2084.

4. Berild D, Mohseni A, Diep LM, Jensenius M, Ringertz SH: Adjustment of antibiotic treatment according to the results of blood cultures leads to decreased antibiotic use and costs. J Antimicrob Chemother 2006, 57:326-330

5. Standiford HC, Chan S, Tripoli M, Weekes E, Forrest GN: Antimicrobial stewardship at a large tertiary care academic medical center: cost analysis before, during, and after a 7-year program. Infect Control Hosp Epidemiol 2012, 33:338-345.

6. Katsios CM, Burry L, Nelson S, Jivraj T, Lapinsky SE, Wax RS, Christian M, Mehta S, Bell CM, Morris AM: An antimicrobial stewardship program improves antimicrobial treatment by culture site and the quality of antimicrobial prescribing in critically ill patients. Crit Care 2012, 16:R216.

7. Rampini SK, Bloemberg GV, Keller PM, Büchler AC, Dollenmaier G, Speck RF, Böttger EC: Broad-range 16S rRNA gene polymerase chain reaction for diagnosis of culture-negative bacterial infections. Clin Infect Dis 2011, 53:1245-1251.

8. Klouche M, Schröder U: Rapid methods for diagnosis of bloodstream infections. Clin Chem Lab Med 2008, 46:888-908.

9. Weinstein MP: Current blood culture methods and systems: clinical concepts, technology, and interpretation of results. Clin Infect Dis 1996, 23:40-46.
10. Brunkhorst FM, Seifert $H$, Kaasch A, Welte $T$ : Shortfalls in the application of blood culture testing in ICU patients with suspected sepsis. DIVI 2010, $1: 23$.

11. Brunkhorst FM, Oppert M, Marx G, Bloos F, Ludewig K, Putensen C, Nierhaus A, Jaschinski U, Meier-Hellmann A, Weyland A, Gründling M, Moerer O, Riessen R, Seibel A, Ragaller M, Büchler MW, John S, Bach F, Spies C, Reill L, Fritz H, Kiehntopf M, Kuhnt E, Bogatsch H, Engel C, Loeffler M, Kollef MH, Reinhart K, Welte T, German Study Group Competence Network Sepsis (SepNet): Effect of empirical treatment with moxifloxacin and meropenem vs meropenem on sepsis-related organ dysfunction in patients with severe sepsis: a randomized trial. JAMA 2012, 307:2390-2399.

12. Engel $C$, Brunkhorst FM, Bone HG, Brunkhorst R, Gerlach H, Grond S, Gruendling M, Huhle G, Jaschinski U, John S, Mayer K, Oppert M, Olthoff D, Quintel M, Ragaller M, Rossaint R, Stuber F, Weiler N, Welte T, Bogatsch H, Hartog C, Loeffler M, Reinhart K: Epidemiology of sepsis in Germany: results from a national prospective multicenter study. Intensive Care Med 2007, 33:606-618.

13. Lee A, Mirrett S, Reller LB, Weinstein MP: Detection of bloodstream infections in adults: how many blood cultures are needed? J Clin Microbiol 2007, 45:3546-3548.

14. Cockerill FR 3rd, Wilson JW, Vetter EA, Goodman KM, Torgerson CA, Harmsen WS, Schleck CD, Ilstrup DM, Washington JA 2nd, Wilson WR: Optimal testing parameters for blood cultures. Clin Infect Dis 2004, 38:1724-1730

15. Tabriz MS, Riederer K, Baran J Jr, Khatib R: Repeating blood cultures during hospital stay: practice pattern at a teaching hospital and a proposal for guidelines. Clin Microbiol Infect 2004, 10:624-627.

16. Seifert H, Abele-Horn M, Fätkenheuer G, Glück T, Jansen B, Kern WV, Mack D, Plum G, Reinert RR, Roos R, Salzberger B, Shah PM, Ullmann U, Weiß M, Welte T, Wisplinghoff $H$, Expertengremium Mikrobiologisch-infektiologische Qualitätsstandards (MiQ). Qualitätssicherungskommission der Deutschen Gesellschaft für Hygiene und Mikrobiologie (DGHM). Zusammen mit der Deutschen Gesellschaft für Hämatologie und Onkologie (DGHO), der Deutschen Gesellschaft für Infektiologie (DGI), der Deutschen Gesellschaft für Internistische Intensivmedizin und Notfallmedizin (DGIIN), der Deutschen Gesellschaft für Pädiatrische Infektiologie (DGPI), der Gesellschaft für Neonatologie und Pädiatrische Intensivmedizin (GNPI) und der Paul-EhrlichGesellschaft für Chemotherapie (PEG): Blutkulturdiagnostik - sepsis, endokarditis, katheterinfektionen. In Mikrobiologisch-infektiologische Qualitätsstandards (MiQ) $3 a$ und 36 2007. Edited by Mauch H, Podbielski A, Herrmann M, Kniehl E. München, Jena: Elsevier GmbH; 2007.

17. Clinical and Laboratory Standards Institute (CLSI): Principles and procedures for blood cultures; approved guideline. CLSI document M47-A (ISBN 1-56238641-7). 940 West Valley Road, Suite 1400, Wayne, Pennsylvania 19087-1898 USA: Clinical and Laboratory Standards Institute; 2007.

18. Hansen S, Schwab F, Behnke M, Carsauw H, Heczko P, Klavs I, Lyytikäinen O, Palomar M, Riesenfeld Orn I, Savey A, Szilagyi E, Valinteliene R, Fabry J, Gastmeier P: National influences on catheter-associated bloodstream infection rates: practices among national surveillance networks participating in the European HELICS project. J Hosp Infect 2009, 71:66-73.

19. European Centre for Disease Prevention and Control: Antimicrobial resistance surveillance in Europe 2010. In Annual Report of the European Antimicrobial Resistance Surveillance Network (EARS-Net). Stockholm: ECDC; 2011.

20. Gastmeier P, Schwab F, Behnke M, Geffers C: [Less blood culture samples: less infections?]. Anaesthesist 2011, 60:902-907.

21. Roscher K: Perspectives of specialization in infectious diseases, an interdisciplinary medical field: the situation in Germany compared to the European and international situation, PhD thesis; 2007. http://www.freidok. uni-freiburg.de/volltexte/4716/.

22. Barriball $\mathrm{KL}$, While $\mathrm{A}$ : Collecting data using a semi-structured interview: a discussion paper. J Adv Nurs 1994, 19:328-335.

23. Cuthbertson $\mathrm{BH}$ : The impact of critical care outreach: is there one? Crit Care 2007, 11:179.

24. Martin GS, Mannino DM, Eaton S, Moss M: The epidemiology of sepsis in the United States from 1979 through 2000. N Engl J Med 2003, 348:1546-1554.

25. Reinhart K, Brunkhorst FM, Bone H-G, Bardutzky J, Dempfle C-E, Forst H, Gastmeier P, Gerlach H, Gründling M, John S, Kern W, Kreymann G, Krüger W, Kujath P, Marggraf G, Martin J, Mayer K, Meier-Hellmann A, Oppert M, Putensen C, Quintel M, Ragaller M, Rossaint R, Seifert H, Spies C, Stüber F, 
Weiler N, Weimann A, Werdan K, Welte T: Prevention, diagnosis, therapy and follow-up care of sepsis: 1st revision of S-2k guidelines of the German Sepsis Society (Deutsche Sepsis-Gesellschaft e.V. (DSG)) and the German Interdisciplinary Association of Intensive Care and Emergency Medicine (DIVI). Edited by Reinhart K, Brunkhorst FM. Stuttgart, New York: Georg Thieme Verlag KG; 2010

26. Progetto LaSER: Lotta alla sepsi in Emilia-Romagna. Razionale, obiettivi, metodi e strumenti. Agenzia sanitaria regionale, Regione Emilia-Romagna (ISSN 1591-223X). viale Aldo Moro 21, 40127 Bologna: Federica Sarti - Agenzia sanitaria regionale dell'Emilia-Romagna, Sistema CDF; 2007.

27. Taking blood cultures - a summary of best practice: Saving lives reducing infection, delivering clean and safe care. London: Department of Health; 2007. Accessed (14th January 2012) via the Department of Health website at: [http://hcai.dh.gov.uk/files/2011/03/Document_Blood_culture_FINAL_ 100826.pdf]

28. Vitrat-Hincky V, François $P$, Labarère J, Recule C, Stahl JP, Pavese P: Appropriateness of blood culture testing parameters in routine practice. Results from a cross-sectional study. Eur J Clin Microbiol Infect Dis 2010, 30:533-539.

29. Willems E, Smismans A, Cartuyvels R, Coppens G, Van Vaerenbergh K, Van den Abeele AM, Frans J, Bilulu Study Group: The preanalytical optimization of blood cultures: a review and the clinical importance of benchmarking in 5 Belgian hospitals. Diagn Microbiol Infect Dis 2012, 73:1-8.

30. Kerremans JJ, van der Bij AK, Goessens W, Verbrugh HA, Vos MC: Needle-toincubator transport time: logistic factors influencing transport time for blood culture specimens. J Clin Microbiol 2009, 47:819-822.

31. Kerremans JJ, van der Bij AK, Goessens W, Verbrugh HA, Vos MC: Immediate incubation of blood cultures outside routine laboratory hours of operation accelerates antibiotic switching. J Clin Microbiol 2009, 47:3520-3523.

32. Jardine MA, Kumar Y, Kausalya S, Harigopal S, Wong J, Shivaram A, Neal TJ, Yoxall CW: Reducing antibiotic use on the neonatal unit by improving communication of blood culture results: a completed audit cycle. Arch Dis Child Fetal Neonatal Ed 2003, 88:F255.

33. Howe RA, Bates CJ, Cowling P, Young N, Spencer RC: Documentation of blood culture results. J Clin Pathol 1995, 48:667-669.

34. Brunkhorst FM, Engel C, Ragaller M, Welte T, Rossaint R, Gerlach H, Mayer K, John S, Stuber F, Weiler N, Oppert M, Moerer O, Bogatsch H, Reinhart K, Loeffler M, Hartog C, German Sepsis Competence Network (SepNet): Practice and perception - a nationwide survey of therapy habits in sepsis. Crit Care Med 2008, 36:2719-2725.

35. Kirn TJ, Weinstein MP: Update on blood cultures: how to obtain, process, report, and interpret. Clin Microbiol Infect 2013, 19:513-520.

doi:10.1186/cc13074

Cite this article as: Schmitz et al:: Quality of blood culture testing - a survey in intensive care units and microbiological laboratories across four European countries. Critical Care 2013 17:R248.

\section{Submit your next manuscript to BioMed Central and take full advantage of:}

- Convenient online submission

- Thorough peer review

- No space constraints or color figure charges

- Immediate publication on acceptance

- Inclusion in PubMed, CAS, Scopus and Google Scholar

- Research which is freely available for redistribution 